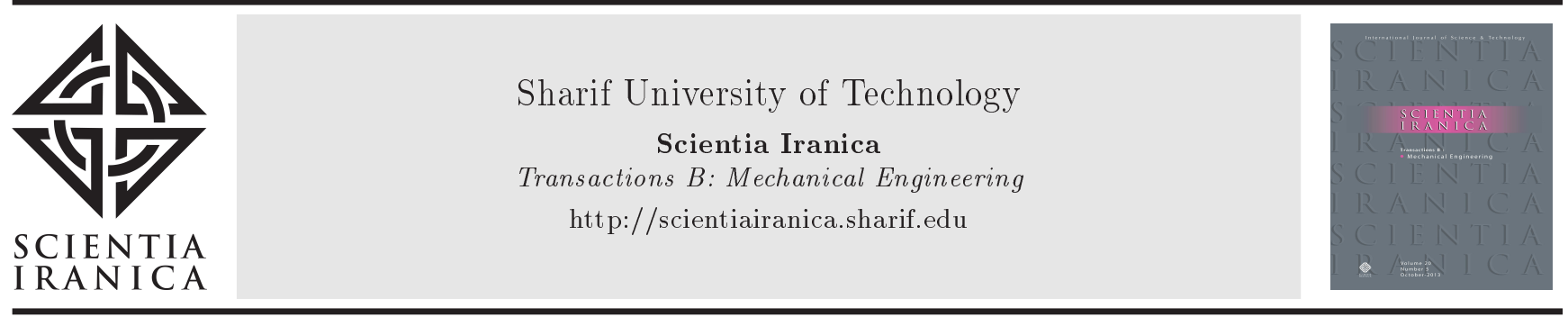

\title{
Fatigue and fracture behavior of A516 steel used in thick-walled pressure vessels
}

\author{
H. Ghasemi ${ }^{a}, *$ R. Masoudi Nejad ${ }^{\mathrm{a}}$, A. Jalayerian Darbandi ${ }^{\mathrm{b}}$, Y. Tadi Beni ${ }^{\mathrm{c}}$, \\ and M. Shariati ${ }^{b}$ \\ a. Department of Mechanical Engineering, Foolad Institute of Technology, Fooladshahr, Isfahan, 84916-63763, Iran. \\ b. Department of Mechanical Engineering, Faculty of Engineering, Ferdowsi University of Mashhad, Mashhad, Iran. \\ c. Faculty of Engineering, Shahrekord University, Shahrekord, Iran.
}

Received 29 October 2018; received in revised form 22 April 2019; accepted 21 July 2019

\section{KEYWORDS}

Fatigue crack growth; Pressure vessel; Fatigue life; Fracture mechanics; Boundary element.

\begin{abstract}
In this paper, the growth of semi-elliptical crack in the walls of thick-walled cylindrical pressure vessels was investigated. The significance of the crack growth in cylindrical pressure vessels provides numerical and experimental 3D models for the growth of fatigue crack and estimates the fatigue life of pressure vessels. Because of available geometric and physical parameters, the fatigue life of these pressure vessels can be predicted more precisely than the existing standard tests, i.e., experimental and numerical. The most common specimen of thick-walled tanks, steel, was analyzed to conduct experimental tests. The mechanical properties and fatigue behavior of A516 steel were determined experimentally. For estimating the crack growth and calculating the fatigue life, the boundary element method and linear fracture mechanics equations were used. Finally, the experimental results of fatigue crack growth were compared with the numerical method, which yielded acceptable results. The overall results showed good agreement between the experimental data and numerical results.
\end{abstract}

(C) 2020 Sharif University of Technology. All rights reserved.

\section{Introduction}

Fatigue crack growth is one of the most important issues in fracture mechanics. The main culprit of many destructions in pressure vessels, which are widely used in the oil and gas industry, is the existing crack in their walls. These cracks may be created by corrosion through the procedures of sheet manufacturing, welding or during the installation of the pressure vessels. In the oil and gas industry, because of noxious chemicals

*. Corresponding author.

E-mail address: hosseinghasemi921@gmail.com (H. Ghasemi)

doi: $10.24200 /$ sci.2019.52119.2546 as well as flammable and explosive materials, it is important to dramatically increase the security of storage systems [1]. Accordingly, many investigations have been carried out on cylindrical pressure vessels and most of these cases are related to the growth of cracks in these pressure vessels [2]. Fatigue crack growth is a phenomenon in which the crack grows very slowly in each loading cycle [3-6]. Most of the systems and pieces, cracked and broken, are subjected to alternating loads in which the magnitude of load is sometimes significantly less than that of the static failure load [7]. In these cases, the main cause of failure is the growth of small cracks in the material, which gradually grow from a very small size to a critical extent. This type of crack growth, which leads to fracture failure, is called fatigue [8-10]. The amount of cracks growth in each loading 
cycle can be calculated by counting the cracks growth lines and comparing them with the loading profile [11]. In the early $1960 \mathrm{~s}$, for the first time, Paris showed that the amount of crack growth in each fatigue loading cycle was controlled by the stress intensity factor at the cracks tip. According to studies by William on the distribution of stress around the crack tip, it was shown that the elastic stresses surrounding the crack tip could be expressed by series. The methods for measuring the stress intensity factors in cracked pieces are analytical, experimental, and computational methods. Different types of loading in cracked pieces include four loading modes [12-15]. The four loading modes include opening of crack surfaces, the slide of cracks on each other, and slide on the outside of sheet surface; if loading is a combination of two or three loading modes, it is called compound loading. In summary, each of the load modes has its own equations. For the first time, the calculation of stresses in the cylindrical pressure vessels was done by Boresi et al. which was called after him [16]. The most important causes of failure include the emergence of surface imperfections during production and corrosion of inner surface of pressure vessels because of an inappropriate acidic environment or the oxidation of that area in the presence of a specific substance inside the pressure vessel. Because of these corrosions, on the surface, fine imperfections are formed as a line of small porosities that cause a stress concentration in the corrosion zone. In many cases, when the pressure vessel has a weld line, failures will begin due to surface imperfections that occur on the weld line during welding. These superficial surface defects are the source of growth and development of semi-elliptical cracks, joining each other and forming a single crack [17]. Surface cracks under tensile load grow in the form of elliptical shape on a thick wall. These walls can be flat, cylindrical, or spherical. Because of the complicated structure of semi-elliptical cracks growing on curved surfaces, crack growth in the flat wall is also considered as an approximation of crack growth in the curved walls; however, by increasing wall thickness and curvature of pressure vessel surfaces, these approximations are not very accurate and reliable. In [18], an attempt was made to improve these approximations for a cylindrical pressure vessel by using weight functions. The calculations required for finding the stress intensity factor were calculated on a perimeter of a semi-elliptical crack in a flat plate under the tensile load. The existing equations were presented in [19], which were used for calculating the stress intensity factor at the crack tip in the radial direction. Moreover, Newman and Raju proposed the equations in [20] to calculate the stress intensity factor on the perimeter of a semielliptical crack in a pressure vessel. To calculate the pressure on vessels designed and, in general, any other structures, there are mainly two criteria for avoiding failures which should be considered. First, the stress intensity factor should not reach the critical value and second, the stress applied to the uncracked section should not exceed the critical stress or, in other words, should not reach the plastic deformation region. To this end, the relationship between the stress intensity factor during failure and the amount of stress at the time of failure can be found by using the experimental data obtained from many failures. Moreover, failure resistance can be predicted in every situation. The results of these studies [21,22] showed that when the pure stress of fracture was less than the flux stress, a linear equation between the maximum stress intensity factor and the amount of stress at the time of failure could be identified [23,24]. In the literature, various problems concerning the fatigue crack growth under pure mode conditions (modes I, II, and III) can be found such as those reported by Silva et al. [25] or Rozumek et al. [26], and Lesiuk et al. [27]. Correia José et al. [28] and Abílio and Correia Jośe [29] used fatigue local models based on strain and SmithWatson-Topper (SWT) relations to model the fatigue crack propagation curves. Correia José et al. [30-33] proposed a procedure for modification of the UniGrow model that uses an elementary material block size, which is obtained from existing Fatigue Crack Growth (FCG) data.

In experimental tests, the geometry of standard specimens has always been used as the basis for measuring experimental data. In this paper, experimental data are obtained by using standard specimens and a new confirmed standard specimen, which is more accurate. The methods of fatigue cracking test and the way of displaying and processing test data are presented in different standards [34]. The study of crack growth behavior is carried out by using the rules and equations of linear elastic fracture mechanics under fatigue loads. For analyzing crack growth, Boundary Element Method (BEM) is employed. Then, the Paris law is used to obtain fatigue life [35]. The intensity factor mode I, which is created in cracking, is more important than the other factors, calculated by the numerical method [36].

\section{Materials and methods}

Mechanical properties including hardness, tensile, Charpy impact, and fatigue growth tests were carried out at room temperature. For this purpose, A516 steel was used due to its widespread applicability to manufacturing thick-walled pressure vessels. By determining material elements, using a metallographic method, and observing an atomic microstructure using non-destructive methods including the use of quantum devices, the initial operations such as thermal operations and the basic state of the material can be 
Table 1. Chemical composition of A516 steel (\%).

\begin{tabular}{ccccccccc}
\hline Material & C & Si & Mn & P & S & Cr & Mo & V \\
\hline A516 & 0.228 & 0.318 & 0.979 & 0.0194 & 0.0166 & 0.066 & 0.005 & 0.013 \\
\hline
\end{tabular}

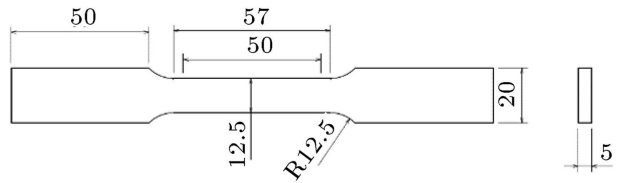

(a)

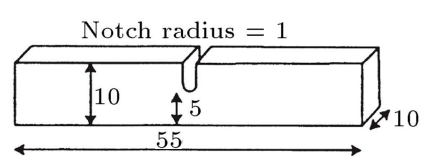

(b)

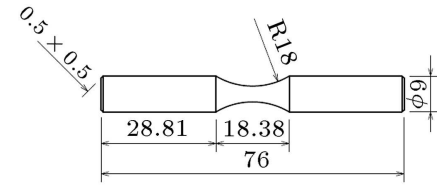

(c)

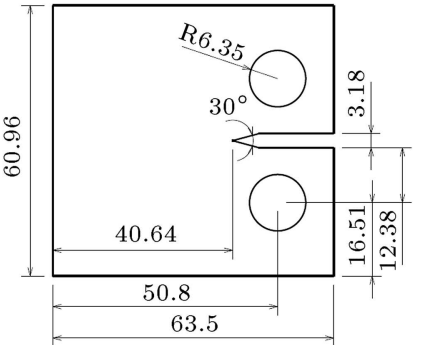

(d)

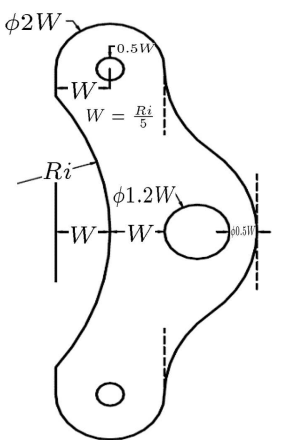

(e)

Figure 1. Geometries of (a) tensile, (b) Charpy impact, (c) fatigue, (d) crack growth rate, and (e) new proposed specimen for fatigue crack growth, and test specimens (dimensions in mm).

determined. By testing, the elements of A516 steel are determined and presented in Table 1 .

To extract the mechanical properties of A516 steel, the tensile test was performed. According to the standard tensile test ASTM E8 [34], specimens as shown in Figure 1(a) were machined and ready for testing, as shown in Figure 1(a). Mechanical properties including yield strength, ultimate tensile strength, relative elongation, and elastic modulus, E, were calculated according to strain-stress curves. Impact resistance of most materials has a direct relation with their malleability. The Charpy impact test was performed according to the ASTM E23 standard at room temperature [37]. For all tests, the impact velocity during impact should be a constant number. The impact velocity in this method is $5-5.5 \mathrm{~m} / \mathrm{s}$. For this test, specimens were manufactured with standard dimensions and V-notch for specimens was formed by standard device. The initial angle with a pendulum velocity of $5 \mathrm{~m} / \mathrm{s}$ is 134 degrees. Figure 1(b) shows the standard specimen of Charpy impact test. To perform a hardness test, the hardness tester was first calibrated and then, a part of the steel was placed under the device. According to the ASTM E10 standard, a $2.5 \mathrm{~mm}$ ball bearing was used. According to the ASTM standard tables for a $2.5 \mathrm{~mm}$ ball bearing and the Brinell hardness test method, a force of $187.5 \mathrm{~kg}$ was chosen [38]. Rotary Bending Fatigue Testing was performed to extract fatigue behavior of A516 steel. Fatigue tests under time-control conditions at room temperature were carried out to determine the S-N curves in the fatigue mode. These curves are plotted in the conditions of the recurrent variable stress cycles (i.e., $\sigma_{m}=0$ ). The amount of stress can be $\sigma_{a}$ or $\sigma_{\max }$. Rotary bending fatigue tests for different specimens can be performed. According to the ASTM E466 standard, the fatigue test specimens are ready to be tested according to Figure 1(c) [39]. In the S$\mathrm{N}$ curve that shows the fatigue strength in terms of the number of cycles, low-cycle fatigue is determined below $10^{3}$ cycles and high-cycle fatigue is above it. On the other hand, below $10^{6}$ or $10^{7}$ cycles, the specimen has a finite life (due to the high operating stress); $10^{6}$ above cycles, the specimen will have an infinite life. For this test, 10 specimens were manufactured with the standard dimensions by CNC machine and excellent surface quality.

In the FCG, the ratio of changes in the length of cracks to the changes in the loading cycle $\left(\frac{d a}{d N}\right)$ shows the amount of crack growth in each loading cycle. In the early 1960s, for the first time, Paris showed that the amount of crack growth in each fatigue loading cycle was controlled by the stress intensity factor at the crack tip [40,41]. For the first time, Paris showed that $K$, $\frac{d a}{d N}$ quantities could be in the form of an exponential equation like Eq. (1):

$$
\frac{d a}{d N}=C(\Delta K)^{n}
$$

where $n$ and $C$ are the material constants dependent on 


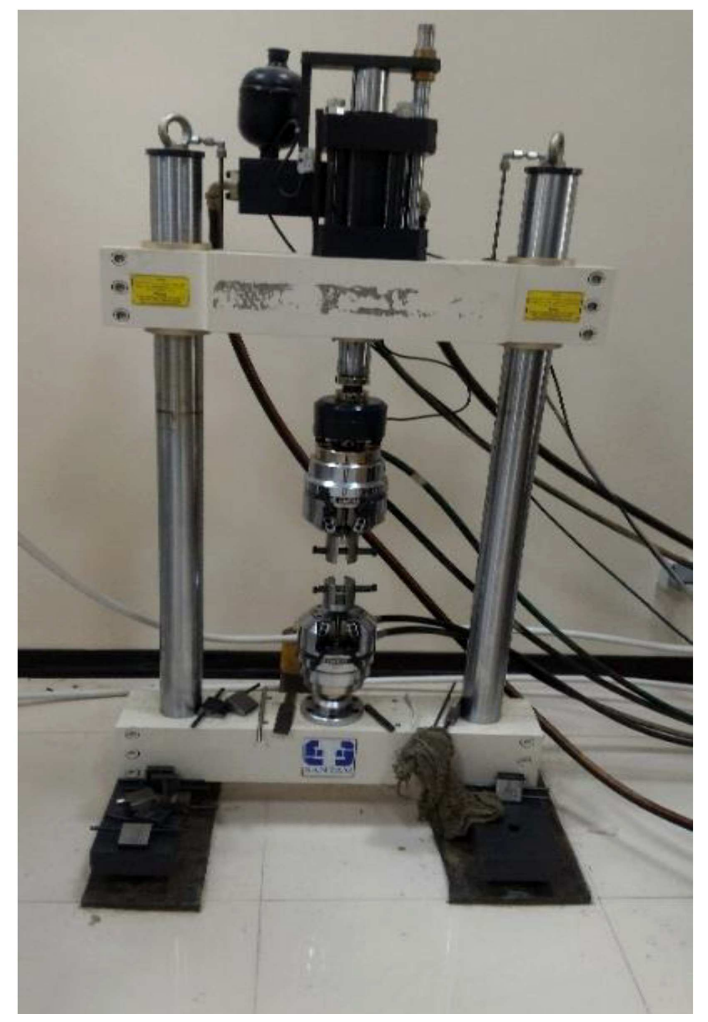

Figure 2. Experimental test setup.

the material FCG under tensile load when $R_{\text {ratio }}=0$.

To investigate the FCG, the test specimens can be either compact tension $\mathrm{C}(\mathrm{T})$ type or sheet with a central crack. This test is usually carried out under constant loading in which the maximum and minimum loads are constant during the experiment. According to the ASTM E647 standard, the dimensions of C(T) specimen are shown in Figure 1(d) [42]. Although the above specimens have already been used as a standard approximation for predicting the behavior of cracks in pressure vessels, either semi-elliptical or general, there is a significant difference between the life of a pressure vessel containing a semi-elliptical crack and standard specimens under the conditions of the same crack growth, which is because of the difference between a pressure vessel and current standard specimens in terms of the FCG behavior. For this reason, by using the research carried out in [43], it was proved that the new proposed specimen was closer to the actual situation. Thus, using the geometry of new specimen for A516 steel, which is highly used in manufacturing pressure vessels, crack growth test was also performed with the new specimen. Figure 1(e) shows the new specimen geometry [44].

To perform this test, the Santam hydraulic device was used. This device is controlled by a computer and has the ability to load up to $50 \mathrm{kN}$ with a frequency of $10 \mathrm{~Hz}$. Figure 2 shows the Santam Fatigue Test device.
To measure the FCG, a camera was installed at the proper location for filming the specimen during the test. For this purpose, it was necessary to install an appropriate index in the place of the crack growth, which measured the amount of crack growth. Figure 3 shows the test specimens of FCG along with the index mounted on them.

After preparing the specimens by using Eq. (2), the following equations can be used for calculating the critical value and load applied to the specimens according to the geometric parameters [45]:

$$
P_{L}=1.072 \times \eta \times B \times b \times \sigma_{y} .
$$

In this equation, $B$ is the thickness of the specimen, $b$ is the width of the specimen, $\sigma_{y}$ is the yield stress obtained using the tensile test, and $\eta$ is the geometric constant calculated by Eq. (3) [45]:

$$
\eta=\sqrt{\left(\frac{2 a}{b}\right)^{2}+\frac{4 a}{b}+2}-\left(\frac{2 a}{b}+1\right) .
$$

By using the provided equations and inserting geometric values, the critical loading value for $\mathrm{C}(\mathrm{T})$ specimens is about $12 \mathrm{kN}$ and for the new specimen is $20 \mathrm{kN}$. The loading force ratio in this test was considered to be 0.1 ( $R=\frac{P_{\min }}{P_{\max }}=0.1$ ). After preparing the specimens and placing them in the device, the load and a frequency of $5 \mathrm{~Hz}$ were applied to the controller computer. The camera was installed in front of the specimen notch and the camera shutter was timed to shoot every 20 seconds. Figure 4 shows broken specimens after the test.

\section{Experimental results and discussion}

\subsection{Metallography}

The surface images were magnified 1000 times (Figure $5)$. Test results showed that the basis structure was ferrite-pearlite, in which the grains were drawn in the direction of rolling. Metallographic investigation showed that the steel had ferrite-pearlite. Due to different intragranular crystal orientations, interlayer distance from one grain to another is different. The average distance between the layers utilizing quantitative metallography was $0.679 \mu \mathrm{m}$.

\subsection{Tensile behavior}

Mechanical properties of A516 steel are presented in Table 2. The results showed that this alloy could be used in pressure vessels due to a sufficient standard tensile strength. Yield strength and ultimate tensile strength were obtained as 408 and $580 \mathrm{MPa}$, respectively, while the elongation at break was $10 \%$. The material had a strain hardening rate of 0.238 , which is a high value for engineering steels.

\subsection{Charpy impact}

Table 3 shows the average Charpy energy for A516 
Table 2. Mechanical properties of A516 steel.

\begin{tabular}{cccc}
\hline Material & $\begin{array}{c}\text { Yield stress } \\
(\mathbf{M P a})\end{array}$ & $\begin{array}{c}\text { Tensile strength } \\
(\mathbf{M P a})\end{array}$ & $\begin{array}{c}\text { Modulus of elasticity } \\
(\mathbf{G P a})\end{array}$ \\
\hline A516 & 408 & 580 & 210 \\
\hline
\end{tabular}

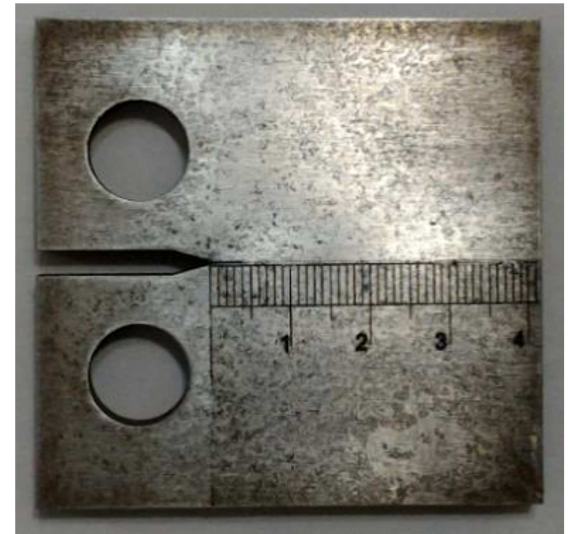

(a)

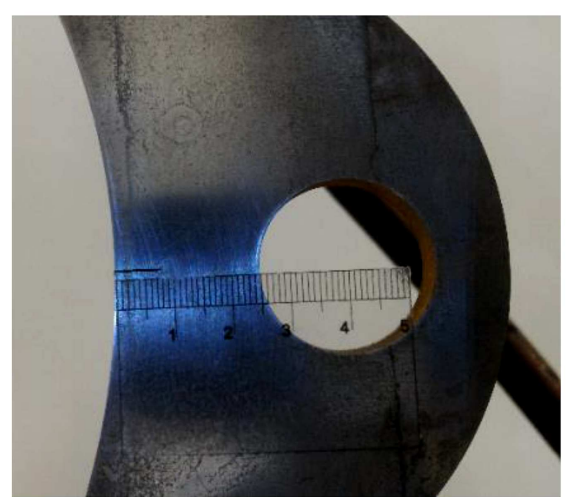

(b)

Figure 3. The index mounted on specimens to measure crack growth: (a) C(T) specimen [43] and (b) new specimen [44].

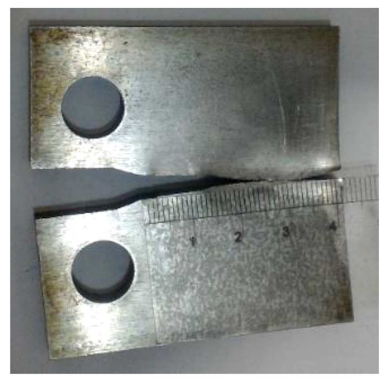

(a)

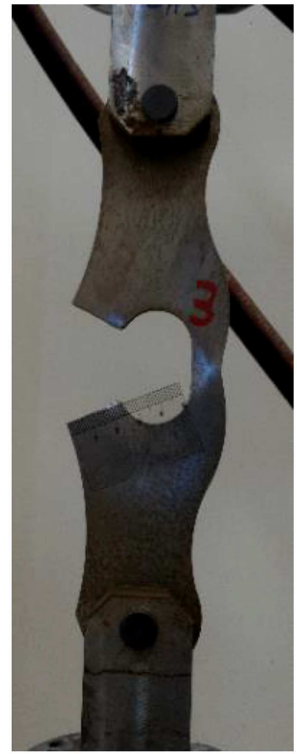

(b)
Figure 4. Test specimens after failure: (a) C(T) specimen and (b) new specimen.

steel. A516 steel requires more energy to fracture the specimens. Lateral expansion of Charpy V-Notch (CVN) specimens on the side of impact and percentage of shear failure fracture surface is inserted in the table. The impact test results showed that the energy absorption for this alloy was very high, which could withstand possible impact and reduce the possibility of explosion.

\subsection{Hardness}

Herein, Brinell static test and the results are presented

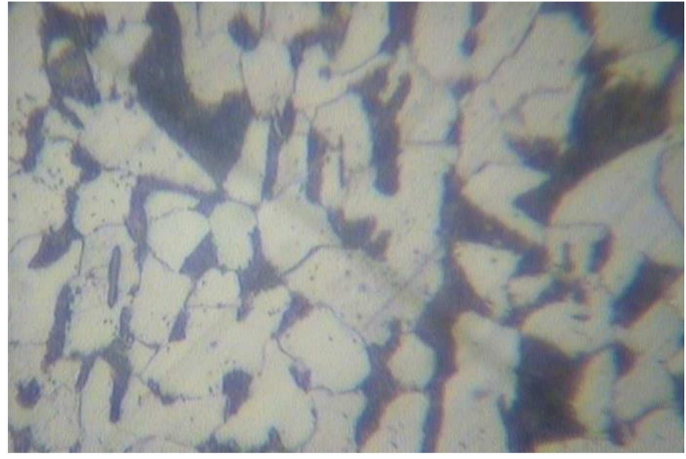

Figure 5. A516 steel ferrite-pearlite basis structure magnification $\times 1000$.

Table 3. Average Charpy energy for A516 steel.

\begin{tabular}{cc}
\hline Specimen & Charpy energy (J) \\
\hline$\# 1$ & 43.6 \\
$\# 2$ & 41.9 \\
$\# 3$ & 40.7 \\
$\# 4$ & 39.6 \\
$\# 5$ & 42.8 \\
Average & 41.7 \\
\hline
\end{tabular}

in Table 4. The results showed that this alloy was characterized by sufficient standard hardness for use in pressure vessels. According to the test results, all the measured hardness data were consistent with the A516 steel specifications.

\subsection{Fatigue performance}

This test was performed according to the ASTM E466 standard. As seen in the general form of S-N curve, by reducing the stress applied to the specimen, the 
Table 4. Hardness test results.

\begin{tabular}{cc}
\hline Location & BHN \\
\hline 1 & 173 \\
2 & 174 \\
3 & 175 \\
Average & 174 \\
\hline
\end{tabular}

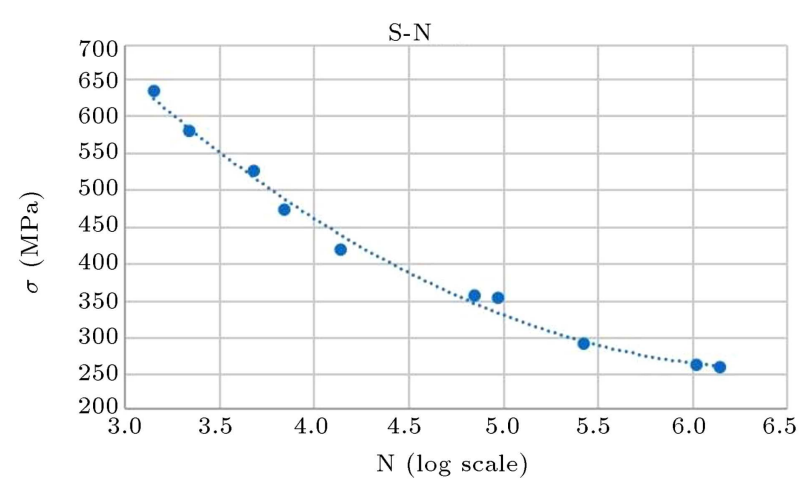

Figure 6. Fatigue S-N curve.

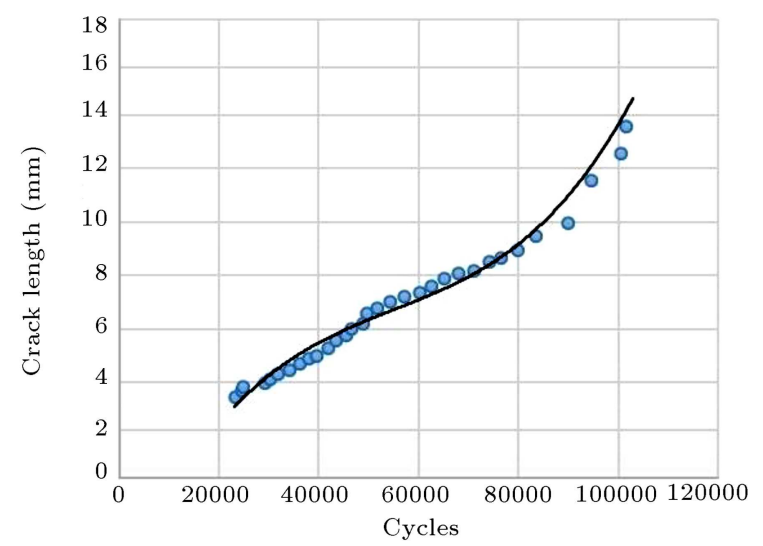

Figure 7. Fatigue life based on the crack length for $\mathrm{C}(\mathrm{T})$ specimen.

fatigue life increased along a horizontal Asymptote. This reduction will stop in a range that the specimen does not fail anymore, and it is called durability of the material. According to the test results, A516 steel does not fail upon stresses less than $250 \mathrm{MPa}$ and it has a finite life with stresses of 400 to $550 \mathrm{MPa}$. Figure 6 shows the S-N curve.

\subsection{Evaluation of FCG}

After testing and measuring the crack growth from the recorded images, the fatigue life curves are plotted in Figures 7 and 8 . By using the gradient of the obtained results and calculating the stress intensity factor with Eq. (4), the crack growth rate was obtained in terms of stress intensity factor. To calculate $\Delta K$, the following equation was used [45]:

$$
\Delta K=\sigma \sqrt{\pi a} .
$$

Here, $a$ is the crack length and $\sigma$ is the stress applied to the cross-sectional area of the specimen.

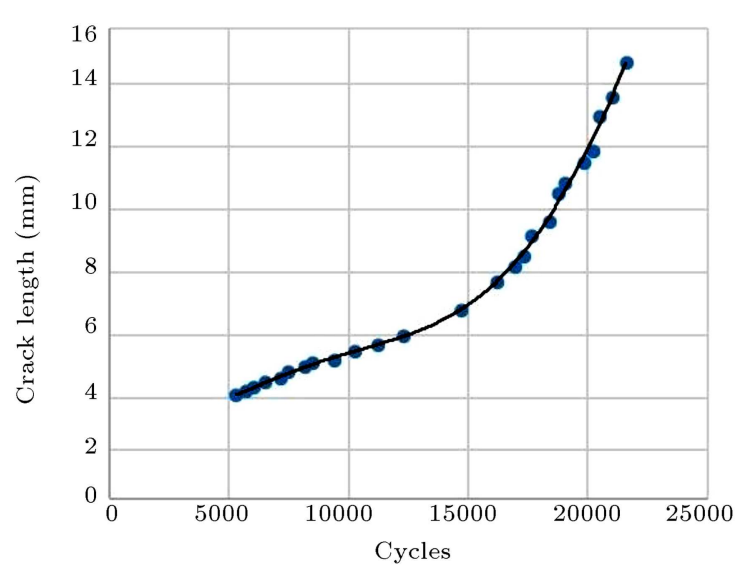

Figure 8. Fatigue life based on the crack length for the new specimen.

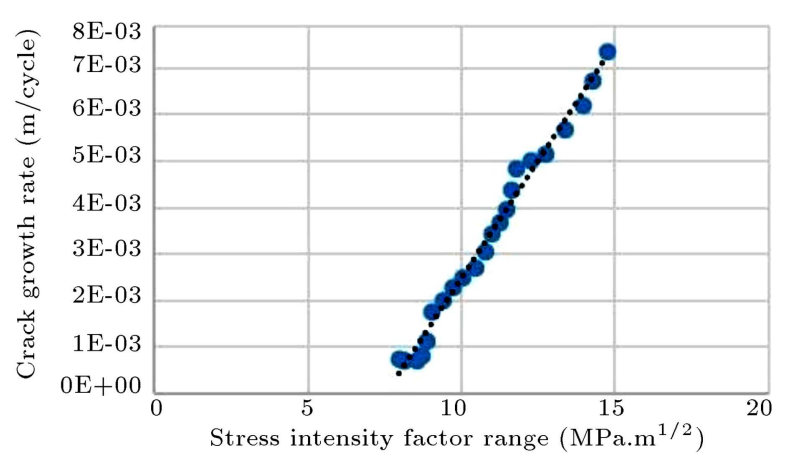

Figure 9. Crack growth rate in terms of stress intensity factor for $\mathrm{C}(\mathrm{T})$ specimen.

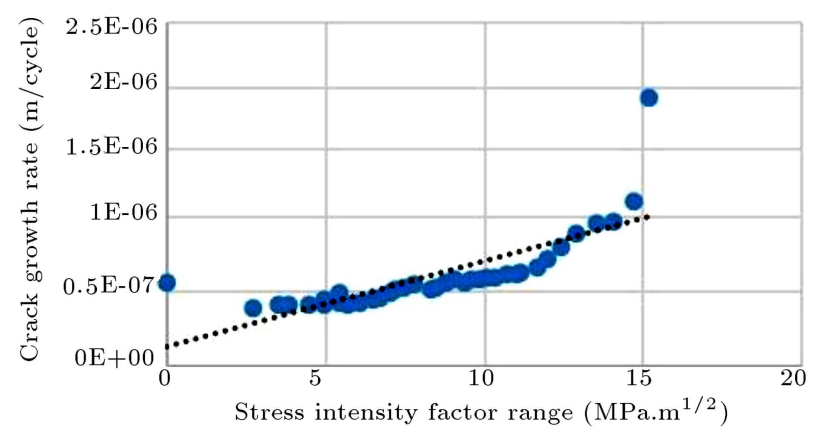

Figure 10. Crack growth rate in terms of stress intensity factor for the new specimen.

In order to find the constant values of the Paris equation, the crack growth rate curves are plotted in terms of stress intensity factor. Figures 9 and 10 show FCG rate in terms of stress intensity factor for $\mathrm{C}(\mathrm{T})$ and new specimens. After plotting the curves, the constants of Paris equation for each specimen are presented in Table 5 .

\section{Numerical method for FCG}

Nowadays, numerical methods solve many complicated problems easily using computers in a short amount 
Table 5. The crack growth constants (or Paris constants) for A516 steel specimen.

\begin{tabular}{ccccc}
\hline Specimen & \multicolumn{2}{c}{$\boldsymbol{C}$} & \multicolumn{2}{c}{$\boldsymbol{n}$} \\
\hline CT \#1 & 1.27 e -12 & $\mathbf{1 . 3 8}$ e $\mathbf{- 1 2}$ & 3.265 & $\mathbf{3 . 3 6 8}$ \\
& & (Avg.) & \multicolumn{3}{c}{} & (Avg.) \\
CT \#2 & 1.38 e -12 & & 3.338 & \\
CT \#3 & 1.49 e -12 & & 3.502 & \\
\hline New \#1 & 8.95 e -13 & $\mathbf{8 . 8 1}$ e $\mathbf{- 1 3}$ & 3.752 & $\mathbf{3 . 7 7 0}$ \\
& & (Avg.) & & (Avg.) \\
New \#2 & 8.77 e -13 & & 3.675 & \\
New \#3 & 8.73 e -13 & & 3.883 & \\
\hline
\end{tabular}

of time. One of these methods is the use of Finite Element Method (FEM) or Boundary Element Method (BEM). While the stress intensity factors for a number of specific geometries exist in books and references, there is no reference for complicated geometries. The best method for calculating crack tip parameters in complicated geometries is using FEM. Because of the singular terms near the crack tip, the stress around the crack tip is calculated by Eq. (5):

$$
\sigma=\frac{K_{I}}{\sqrt{2 \pi r}} f(\theta) .
$$

In the above equation, the stress is a function of $\frac{1}{\sqrt{r}}$ in which near the crack tip, $r$ tends to zero and as a result, stress tends to infinity. After defining the loading vector and the hardness matrix as well as applying the fixed boundary conditions, the finite element software was used to perform static analysis and consequently, to calculate the stress-intensity factor using the analysis results and Eqs. (6)-(10):

$$
\begin{aligned}
& \sigma_{x x} \sqrt{2 \pi r}=K_{I} \cos \frac{\theta}{2}\left(1-\sin \frac{\theta}{2} \cdot \sin \frac{3 \theta}{2}\right) \\
& \sigma_{y y} \sqrt{2 \pi r}=K_{I} \cos \frac{\theta}{2}\left(1+\sin \frac{\theta}{2} \cdot \sin \frac{3 \theta}{2}\right) \\
& u_{x}=\frac{K_{I}}{2 E} \sqrt{\frac{r}{2 \pi}}(1+\nu)\left[(2 \kappa-1) \cos \frac{\theta}{2}-\cos \frac{3 \theta}{2}\right] \\
& u_{x}=\frac{K_{I}}{2 E} \sqrt{\frac{r}{2 \pi}}(1+\nu)\left[(2 \kappa+1) \sin \frac{\theta}{2}-\sin \frac{3 \theta}{2}\right] \\
& \left\{\begin{array}{l}
\kappa=3-4 \nu \\
\kappa=\frac{3-4 \nu}{1+\nu}
\end{array}\right.
\end{aligned}
$$

In the above equations, $r$ is the distance from the crack tip and $\theta$ is the angle at which the stresses are calculated.

In order to simulate FCG and estimate A516 steel life, modeling was done using Franc 3D software, i.e., a software product for studying crack growth in $3 \mathrm{D}$ geometric shapes, designed by researchers at Cornell University [46].

\subsection{Finite Element Method (FEM)}

The number of elements is selected after different meshing. Here, the size of elements is $3 \mathrm{~mm}$ and a quadrilateral element is selected. The number of appropriate elements was 1216 and 4130 for the $\mathrm{C}(\mathrm{T})$ specimen and the new specimen, respectively. Figure 11 shows the finite element model of $\mathrm{C}(\mathrm{T})$ specimen and the new specimen. Also, all the properties of the material and the applied load are the same as the experimental tests.

The stress-strain analysis results with similar loading in the experimental tests for the $\mathrm{C}(\mathrm{T})$ specimen are shown in Figure 12(a). All the steps were also performed for the new specimen. Also, the maximum stress obtained for the new specimen is shown in Figure 12(b).

\subsection{Boundary Element Method (BEM)}

Franc3D software was created and developed by Cornell University. The purpose of this software is to simulate the three-dimensional crack growth of industrial components in relatively complicated conditions. Figure 13 shows the geometric modeling of specimens in the software.

To solve the problem correctly and to ensure its accuracy, the meshing must be done correctly. The larger the number of elements, the higher the accuracy; however, the problem-solving speed is reduced. In order to make sure the problem is solved accurately, the number of elements must be increased as much as possible. To find the number of appropriate elements, the problem was solved with a number of different elements several times. According to Tables 6 and 7 ,

Table 6. The number of elements for the $\mathrm{C}(\mathrm{T})$ specimen.

\begin{tabular}{ccc}
\hline Step & $\begin{array}{c}\text { Number of } \\
\text { elements }\end{array}$ & $\begin{array}{c}\text { Stress Intensity Factor } \\
\text { (MPa.mm }^{\mathbf{0 . 5}} \text { ) }\end{array}$ \\
\hline 1 & 356 & 2.81 \\
2 & 496 & 2.72 \\
3 & 1218 & 2.48 \\
4 & 1305 & 2.47 \\
5 & 1674 & 2.47 \\
6 & 2142 & 2.47 \\
\hline
\end{tabular}

Table 7. The number of elements for the new specimen.

\begin{tabular}{ccc}
\hline Step & $\begin{array}{c}\text { Number of } \\
\text { elements }\end{array}$ & $\begin{array}{c}\text { Stress Intensity Factor } \\
\text { (MPa.mm }^{\mathbf{0 . 5}} \text { ) }\end{array}$ \\
\hline 1 & 735 & 1.77 \\
2 & 1060 & 1.70 \\
3 & 1156 & 1.63 \\
4 & 2799 & 1.59 \\
5 & 3110 & 1.59 \\
6 & 4311 & 1.59 \\
\hline
\end{tabular}




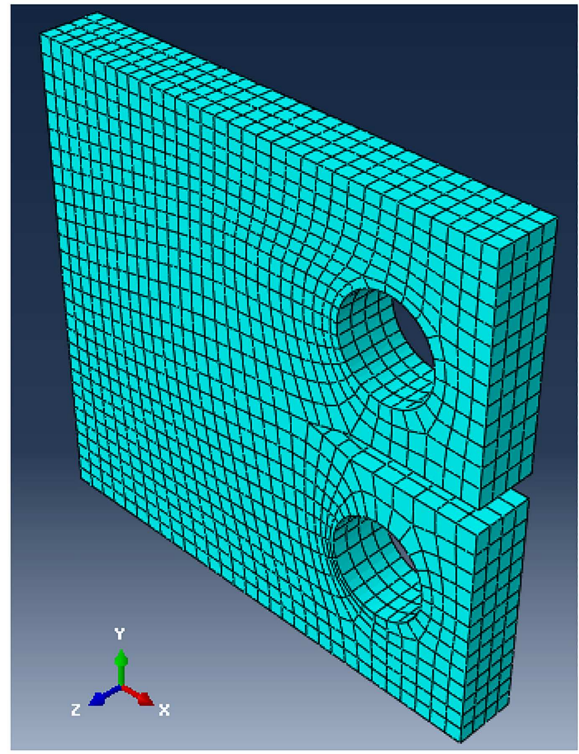

(a)

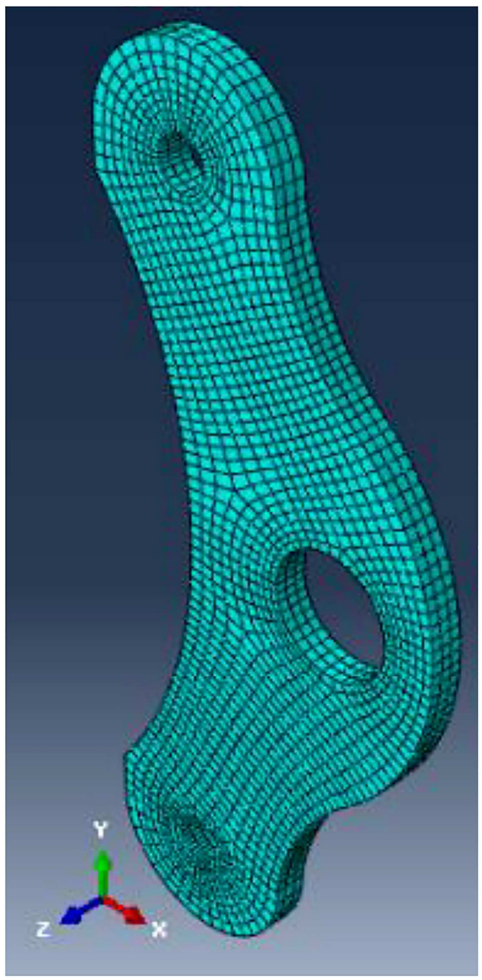

(b)

Figure 11. Finite element model: (a) $\mathrm{C}(\mathrm{T})$ specimen and (b) new specimen.

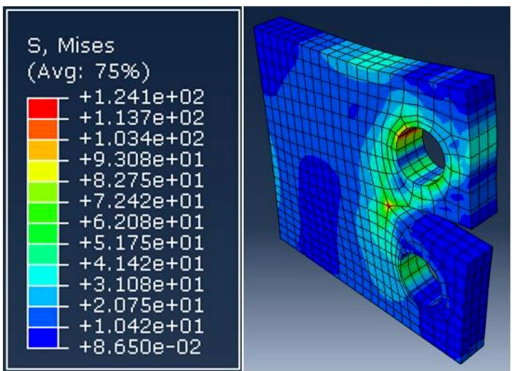

(a)

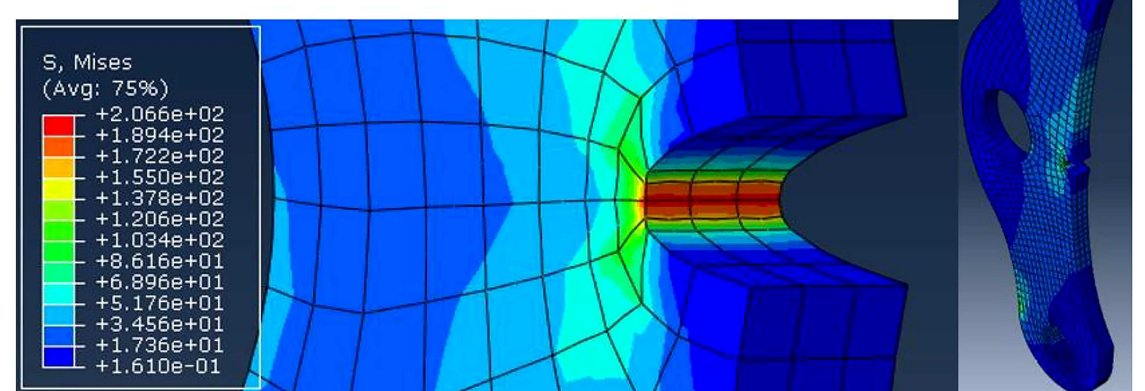

(b)

Figure 12. The maximum von-Mises stress: (a) $\mathrm{C}(\mathrm{T})$ specimen and (b) new specimen.

the number of appropriate elements was selected for the $\mathrm{C}(\mathrm{T})$ specimens and the new specimen, respectively. The number of appropriate elements for the $\mathrm{C}(\mathrm{T})$ specimen and the arch form of the new specimen was 1218 and 2799 elements, respectively.

To create the initial crack on the specimen, the semi-elliptical crack was used according to Figure 14 with dimensions of $a=5 \mathrm{~mm}$ and $b=3 \mathrm{~mm}$. Figure 15 shows the location of the initial crack and its surrounding element.

The next steps of the boundary element model including the definition of material properties, meshing, boundary conditions, and solving are taken. Quadrilateral elements with four nodes can be used for meshing. After loading, the specimen is meshed and the stress analysis is performed through the Boundary Element Solver (BES) software. Then, the stress-intensity factor values are calculated in all the three modes. In the presence of stress intensity factor, the direction of crack growth is also determined. The crack growth rate is optional. The crack tip curve can be fit after determining the direction of crack growth and crack growth can be simulated for another step. In order to develop the crack by BEM, first, the crack tip is 


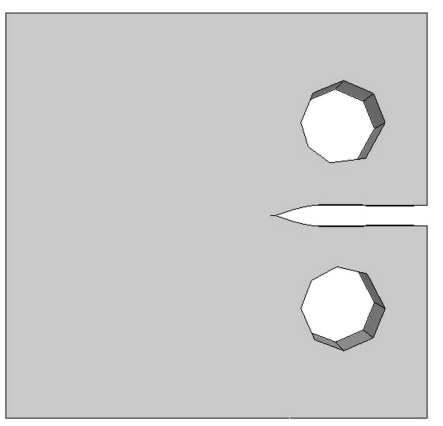

(a)

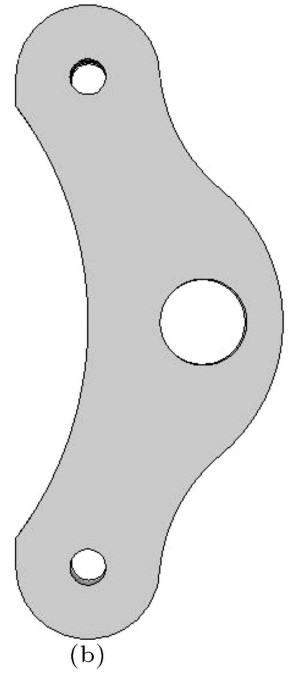

Figure 13. Boundary element model in Franc3D software: (a) $\mathrm{C}(\mathrm{T})$ specimen and (b) the new specimen.

divided into several elements. The number of divisions is optional and the user will choose it. After the crack growth, the specimen is re-meshed and prepared for solving. This process is repeated for each step to develop the crack to the expected rate. Figure 16 shows the crack after 44 growth steps in $\mathrm{C}(\mathrm{T})$ specimen. Figure 17 shows the crack after 40 growth steps.

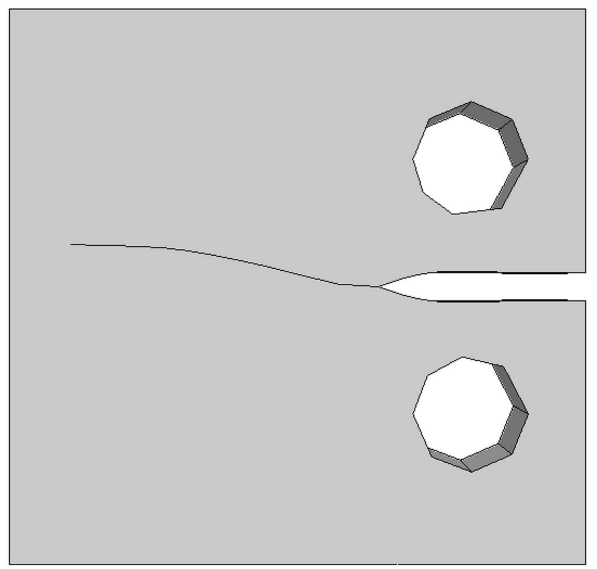

Figure 16. The crack after 44 growth steps in $\mathrm{C}(\mathrm{T})$ specimen.

The results for the stress-intensity factors at the crack tip in terms of the crack length for the $\mathrm{C}(\mathrm{T})$ specimen and the new specimen are given in Figure 18(a) and (b), respectively.

\subsection{Comparison of results}

In this study, the measurement of FCG rate in pressure vessels was investigated using experimental and numerical methods. A new standard specimen was chosen for this test [20]. For the first time, a pressure

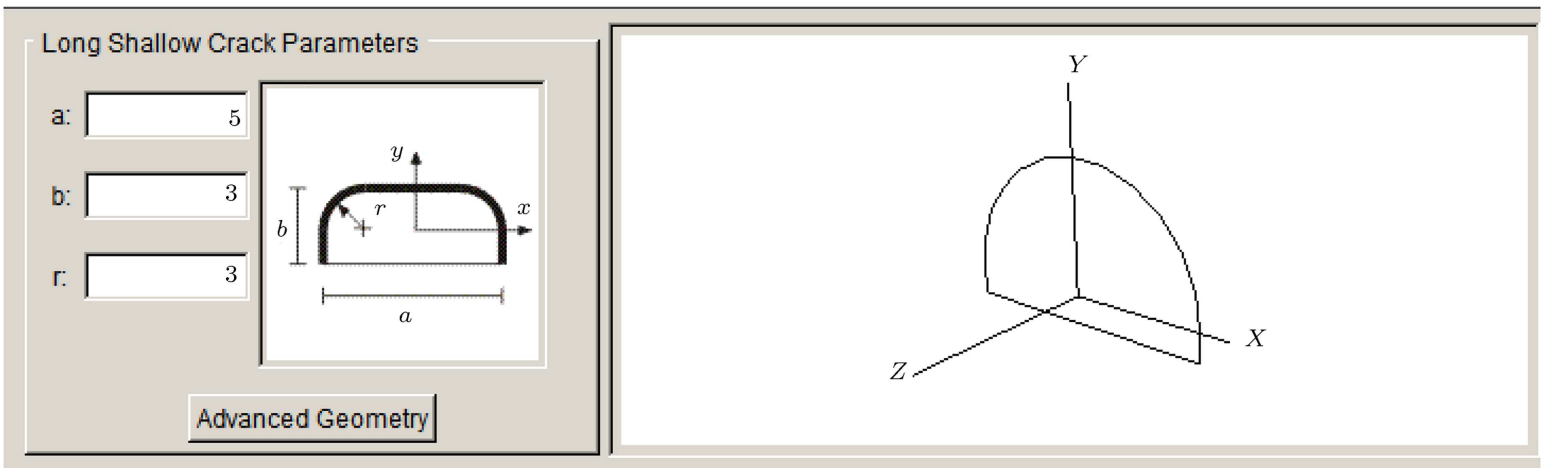

Figure 14. Geometry of initial crack.

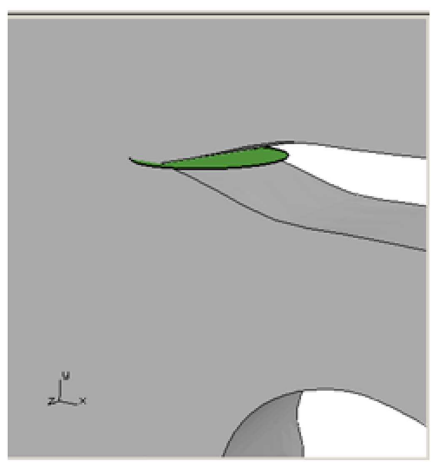

(a)

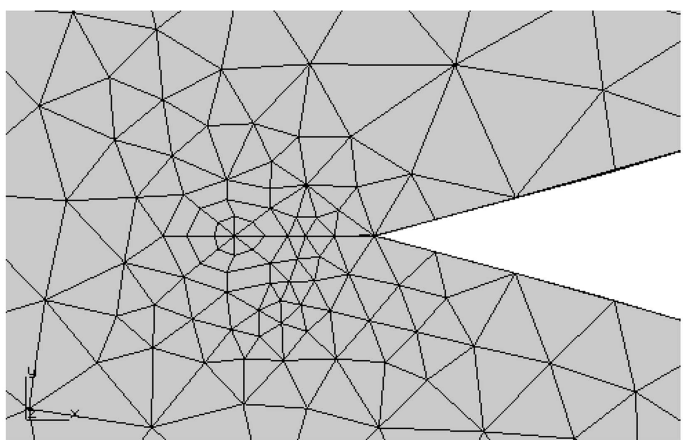

(b)

Figure 15. Geometry and location of the initial crack: (a) Location of the initial crack and (b) the surroundings of the crack tip. 


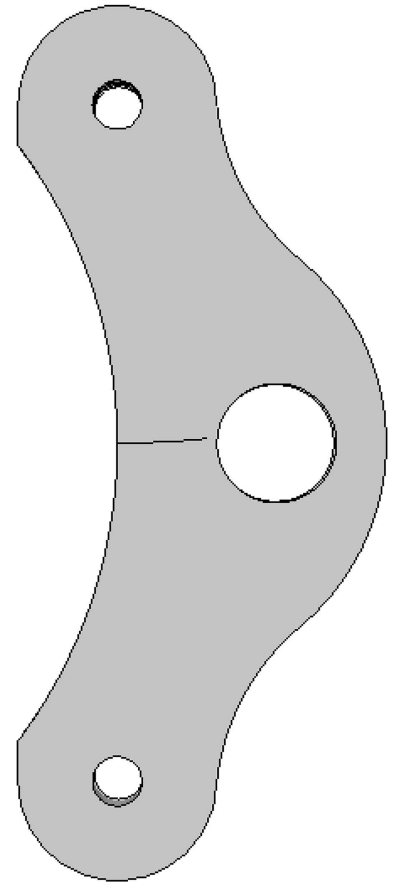

Figure 17. The crack after 40 growth steps in the new specimen.

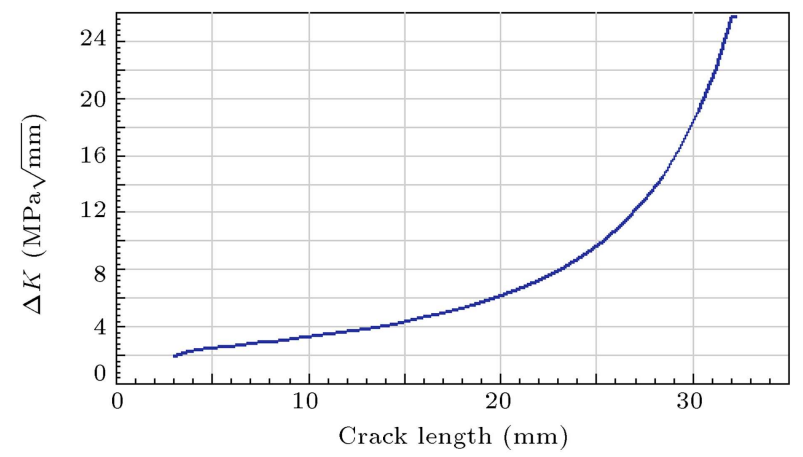

(a)

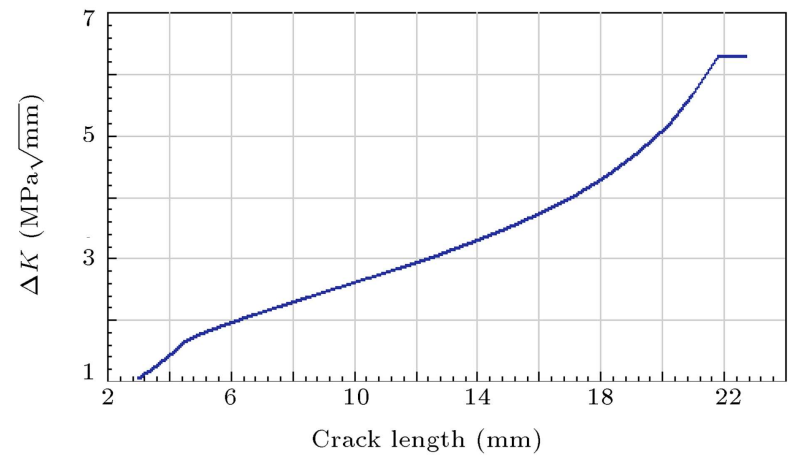

(b)

Figure 18. Stress intensity factor in terms of the crack length: (a) $\mathrm{C}(\mathrm{T})$ specimen and (b) the new specimen.

vessel made of sheet with a new specimen in the form of arch was tested for FCG. Standard specimens were loaded with a constant range and values of $21 \mathrm{kN}$ for the new specimen and $12 \mathrm{kN}$ for the $\mathrm{C}(\mathrm{T})$ specimen.

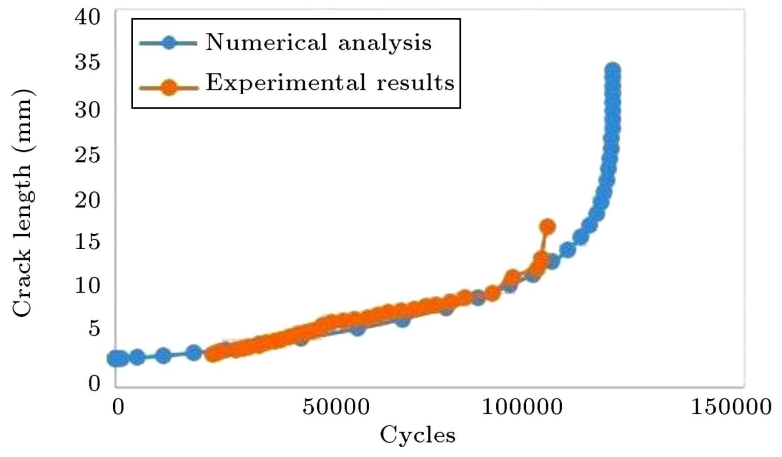

(a)

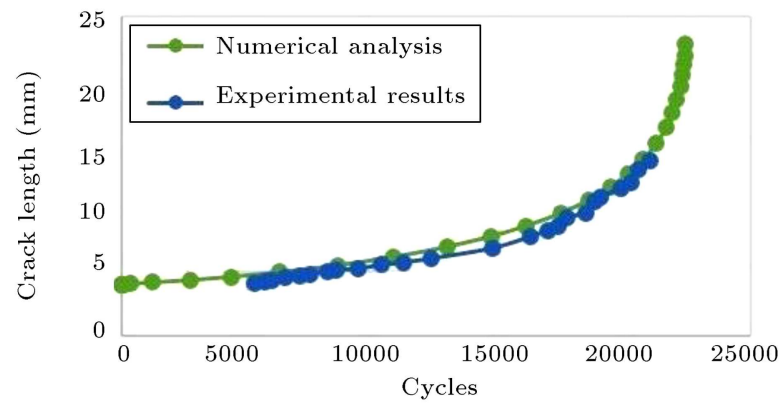

(b)

Figure 19. Fatigue life in terms of crack length: (a) $C(T)$ specimen and (b) the new specimen.

According to the loading, the value of stress applied to the new specimen notch is $180 \mathrm{MPa}$ and the value of stress applied to the $\mathrm{C}(\mathrm{T})$ specimen is $115 \mathrm{MPa}$. In the following, the results of experimental and numerical tests are compared. Figure 19(a) shows the fatigue life of $\mathrm{C}(\mathrm{T})$ specimen in comparison with the numerical results. Figure 19(b) shows the fatigue life curve of the new specimen in comparison with the numerical results.

The maximum lifetime of the new specimen and the standard specimen after reaching the threshold of the stress intensity factor is tabulated in Figure 19. This means that by increasing the length of the initial crack, the volume of the load will decrease to some extent such that the stress intensity factor at the top of the crack will be equal to the threshold value. From the obtained results, it is inferred that the conformity of the newly introduced specimen for testing the crack in the pressure vessels is higher than that of the existing ones. The average error of the $\mathrm{C}(\mathrm{T})$ specimen and the new specimen is $20 \%$ and $7 \%$, respectively. According to Figure 19, there is very good agreement between the results for the new specimen and the cylindrical vessel. This specimen can be suggested to measure FCG in the thick-walled pressure vessels.

\section{Conclusions}

In this study, the mechanical performance focusing on the fatigue and fracture behavior of A516 steel was evaluated by considering a set of related parameters, 
both experimentally and numerically. The results of this study can be used to determine the fatigue life of thick-walled pressure vessels accurately by considering the shortest time, the lowest price, and calculations. To measure the fatigue crack growth rate in this study, a new proposed specimen was used by which for the first time, the steel used in pressure vessels was investigated with this new specimen. The results of fatigue loading on new specimen were compared with those of fatigue loading in the standard specimen. Finite element method, boundary element method, and experimental method were employed to investigate the behavior of fatigue crack growth in the specimen. For this purpose, a three-dimensional model was conducted. Fatigue test was carried out on a couple of specimens made of A516 with a new geometry in order to verify the numerical results. The most significant results of this study can be presented as follows:

1. According to the flat $\mathrm{S}-\mathrm{N}$ curve with a fatigue limit slightly higher than the yield point of the material, A516 steel showed high fatigue strength. Also, the level of fatigue failure of this steel was of cleavage type, which generally led to brittle behavior of the material;

2. Cracks play an important role in initiation of fatigue crack in thick-wall pressure vessels. Effects of size and direction of cracks are important;

3. The results of boundary element method were compared with those achieved by experimental tests. The numerical analysis results obtained showed good agreement with those obtained from experimental results;

4. Slope of fatigue life curve in terms of crack length, initial part and along small cracks is very low. In other words, a small increase in crack length led to a great growth in the fatigue life. Therefore, the direction of stress intensity factor along small cracks was considered much more important than that of stress intensity factor along large cracks;

5. By comparing the new specimen results with other existing specimens, it was found that the new specimen led to more accurate results and less error than the other existing ones.

Also, other effects such as loading frequency, temperature, and surface smoothness in the material life and the ratio of surface properties need to be investigated in the future.

\section{References}

1. Rickerby, D.G. and Fenici, P. "Simultaneous light ion irradiation and fatigue experiment for the Ispra cyclotron", Journal of Nuclear Materials, 104, pp. 1577-1581 (1981).
2. Mackerle, J. "Finite elements in the analysis of pressure vessels and piping, an addendum: A bibliography (2001-2004)", International Journal of Pressure Vessels and Piping, 82(7), pp. 571-592 (2005).

3. Masoudi Nejad, R. "Rolling contact fatigue analysis under influence of residual stresses", MS Thesis, Sharif University of Technology, School of Mechanical Engineering (2013).

4. Masoudi Nejad, R., Salehi, S.M., and Farrahi, G.H. "Simulation of railroad crack growth life under the influence of combination mechanical contact and thermal loads", in 3rd International Conference on Recent Advances in Railway Engineering, Iran (2013).

5. Masoudi Nejad, R., Salehi, S.M., Farrahi, G.H., and Chamani, M. "Simulation of crack propagation of fatigue in Iran rail road wheels and effect of residual stresses", In: Proceedings of the 21st International Conference on Mechanical Engineering, Iran (2013).

6. Salehi, S.M., Farrahi, G.H., Sohrabpoor, S., and Masoudi Nejad, R. "Life estimation in the railway wheels under the influence of residual stress field", International Journal of Railway Research, 1(1), pp. 53-60 (2014).

7. Hadipour, M., Alambeigi, F., Hosseini, R., and Masoudinejad, R. "A study on the vibrational effects of adding an auxiliary chassis to a 6-ton truck", Journal of American Science, 7(6), pp. 1219-1226 (2011).

8. Aliakbari, K., Imanparast, M., and Masoudi Nejad, R. "Microstructure and fatigue fracture mechanism for a heavy-duty truck diesel engine crankshaft", Scientia Iranica, 26(6), pp. 3313-3324 (2019).

9. Masoudi Nejad, R., Shariati, M., Farhangdoost, Kh., and Atrian, A. "Rolling contact fatigue analysis of rails under the influence of residual stresses induced by manufacturing", Scientia Iranica, 26(3), pp. 14271437 (2019).

10. Masoudi Nejad, R., Farhangdoost, Kh., Shariati, M., and Moavenian, M. "Stress intensity factors evaluation for rolling contact fatigue cracks in rails", Tribology Transactions, 60(4), pp. 645-652 (2016).

11. Ghahremani Moghadam, D., Farhangdoost, Kh., and Masoudi Nejad, R. "Microstructure and residual stress distributions under the influence of welding speed in friction stir welded 2024 aluminum alloy", Metallurgical and Materials Transactions B, 47(3), pp. 20482062 (2016).

12. Masoudi Nejad, R., Farhangdoost, Kh., and Shariati, M. "Numerical study on fatigue crack growth in railway wheels under the influence of residual stresses", Engineering Failure Analysis, 52, pp. 75-89 (2015).

13. Masoudi Nejad, R., Farhangdoost, Kh., and Shariati, M. "Three-dimensional simulation of rolling contact fatigue crack growth in UIC60 rails", Tribology Transactions, 59(6), pp. 1059-1069 (2016).

14. Shariati, M. and Masoudi Nejad, R. "Fatigue strength and fatigue fracture mechanism for spot welds in Ushape specimens", Latin American Journal of Solids and Structures, 13(15), pp. 2787-2801 (2016). 
15. Masoudi Nejad, R., Shariati, M., and Farhangdoost, Kh. "Effect of wear on rolling contact fatigue crack growth in rails", Tribology International, 94, pp. 118125 (2016).

16. Boresi, A.P., Chong, K., and Lee, J.D., Elasticity in Engineering Mechanics, Second Ed., John Wiley \& Sons (2010).

17. Thurlbeck, S.D. "A fracture mechanics based methodology for the assessment of weld toe cracks in tubular offshore joints", Ph.D. Thesis, University of Manchester, Institute of Science and Technology (1991).

18. Zheng, X.J., Kiciak, A., and Glinka, G. "Weight functions and stress intensity factors for internal surface semi-elliptical crack in thick-walled cylinder", Engineering Fracture Mechanics, 58(3), pp. 207-221 (1997).

19. Anderson, T.L. "Fracture mechanics-fundamentals and applications", NASA STI/Recon Technical Report (1991).

20. Newman, J.C. and Raju, I.S. "Stress-intensity factors for internal surface cracks in cylindrical pressure vessels", Journal of Pressure Vessel Technology, 102(4), pp. 342-346 (1980).

21. Perl, M. and Levinsohn, J.A. "Measurement of the actual fracture toughness of a maraging 300 pressurized cylinder using the vessel as the test specimen", Engineering Fracture Mechanics, 34(2), pp. 525-530 (1989).

22. Newman, J.C. "Fracture analysis of various cracked configurations in sheet and plate materials", In Properties Related to Fracture Toughness, ASTM International, 605(1), pp. 104-123 (1976).

23. Masoudi Nejad, R. "Using three-dimensional finite element analysis for simulation of residual stresses in railway wheels", Engineering Failure Analysis, 45, pp. 449-455 (2014).

24. Masoudi Nejad, R., Shariati, M., and Farhangdoost, Kh. "3D finite element simulation of residual stresses in UIC60 rails during the quenching process", Thermal Science, 21(3), pp. 1301-1307 (2017).

25. Silva, A.L.L., Jesus, D., Xavier, A.M.P, Correia José, A.F.O., and Fernandes, A. "Combined analyticalnumerical methodologies for the evaluation of mixedmode (I+II) fatigue crack growth rates in structural steels", Engineering Fracture Mechanics, 185, pp. 124138 (2017).

26. Rozumek, D., Marciniak, Z., Lesiuk, G., Correia, J.A., and de Jesus, A.M. "Experimental and numerical investigation of mixed mode I+ II and I+ III fatigue crack growth in S355J0 steel", International Journal of Fatigue, 113, pp. 160-170 (2018).

27. Lesiuk, G., Kucharski, P., Correia, J.A., De Jesus, A.M.P., Rebelo, C., and da Silva, L.S. "Mixed mode (I+ II) fatigue crack growth in puddle iron", Engineering Fracture Mechanics, 185, pp. 175-192 (2017).
28. Correia José, A.F.O., Abilio, M.P., and FernándezCanteli, A. "A procedure to derive probabilistic fatigue crack propagation data", International Journal of Structural Integrity, 3(2), pp. 158-183 (2012).

29. Abílio, M.P. and Correia José, A.F.O. "Critical assessment of a local strain-based fatigue crack growth model using experimental data available for the P355NL1 steel", Journal of Pressure Vessel Technology, 135(1), pp. 11-40 (2013).

30. Correia José, A.F.O., Abílio, M.P., and FernándezCanteli, A. "Local unified probabilistic model for fatigue crack initiation and propagation: application to a notched geometry", Engineering Structures, 52, pp. 394-407 (2013).

31. Correia José, A.F.O., Huffman, P.J., Abílio, M.P., Cicero, S., Fernández-Canteli, A., Berto, F., and Glinka, G. "Unified two-stage fatigue methodology based on a probabilistic damage model applied to structural details", Theoretical and Applied Fracture Mechanics, 92, pp. 252-265 (2017).

32. Correia José, A.F.O., Abílio, M.P., Moreira, P.M., and Tavares, P.J. "Crack closure effects on fatigue crack propagation rates: application of a proposed theoretical model", Advances in Materials Science and Engineering, 2016, pp. 13-24 (2016).

33. Correia José, A.F.O, Blasón, S., Arcari, A., Calvente, M., Apetre, N., Moreira, P.M.G.P., De Jesus, A.M.P., and Canteli, A.F. "Modified CCS fatigue crack growth model for the AA2019-T851 based on plasticity-induced crack-closure", Theoretical and Applied Fracture Mechanics, 85, pp. 26-36 (2016).

34. ASTM E8, Standard Test Methods for Tension Testing of Metallic Materials (2012).

35. Masoudi Nejad, R. "Three-dimensional analysis of rolling contact fatigue crack and life prediction in railway wheels and rails under residual stresses and wear", Ph. D. Thesis, Ferdowsi University of Mashhad, School of Mechanical Engineering (2017).

36. Masoudi Nejad, R., Farhangdoost, Kh., and Shariati, M. "Microstructural analysis and fatigue fracture behavior of rail steel", Mechanics of Advanced Materials and Structures, 27(2), pp. 152-164 (2020).

37. ASTM E23, Standard Test Methods for Notched Bar Impact Testing of Metallic Materials (2012).

38. ASTM E10-10, Standard Test Methods for Brinell hardness of Metallic Materials (2012).

39. ASTM E466-07, Standard Practice for Conducting Force Controlled Constant Amplitude Axial Fatigue Tests of Metallic Materials (2012).

40. Shariati, M., Mirzaei, M., and Masoudi Nejad, R. "An applied method for fatigue life assessment of engineering components using rigid-insert crack closure model", Engineering Fracture Mechanics, 204, pp. 421-433 (2018). 
41. Masoudi Nejad, R., Shariati, M., and Farhangdoost, Kh. "Prediction of fatigue crack propagation and fractography of rail steel", Theoretical and Applied Fracture Mechanics, 101, pp. 320-331 (2019).

42. ASTM E647-11, Standard Test Method for Measurement of Fatigue Crack Growth Rates (2011).

43. Shariati, M., Mohammadi, E., and Masoudi Nejad, R. "Effect of a new specimen size on fatigue crack growth behavior in thick-walled pressure vessels", International Journal of Pressure Vessels and Piping, 150, pp. 1-10 (2017).

44. ASTM designation E-399-83, Standard Method of Test for Plane-Strain Fracture Toughness of Metallic Materials, ASTM Annual Standards, 03.01 (2011).

45. Anderson, T.L., Fracture Mechanics: Fundamentals and Applications, Second Ed., CRC press (2017).

46. Cornell Fracture Group, Accessed 15 March (2016). http://www.cfg.cornell.edu

\section{Biographies}

Hossein Ghasemi received the MSc degree from Foolad Institute of Technology, Iran. His research interests are in the areas of boundary element, fracture mechanics, and residual stress prediction.

Reza Masoudi Nejad received the PhD degree from Ferdowsi University of Mashhad, Iran. He is currently an Assistant Professor in Mechanical Engineering at Foolad Institute of Technology, Iran. To date, he has published more than 27 journal and 13 conference papers. He has recently published a book named
"Mechanical design of electromechanical systems in micro-nano scale", in Sharif University of Technology Publishing. His research interests are in the areas of finite element, fatigue and fracture mechanics, stresses, fatigue and friction of rolling/sliding, surface science, and residual stress measurement and prediction.

Ahmad Jalayerian Darbandi received the BSc degree from Ferdowsi University of Mashhad, Iran. His research interests are in the areas of experimental mechanics, fracture mechanics, and stress analysis.

Yaghoub Tadi Beni obtained his PhD degree in Mechanical Engineering from Sharif University of Technology, Tehran, Iran and is currently a Professor of Mechanical Engineering at Shahrekord University, Iran. To date, he has published more than 94 journal and 36 conference papers. His research interests include nano-mechanics/nano-structure stability, nonlinear/nonclassical continuum mechanics, nonlinear analysis of beam and plates and shells, nonlinear finite element method, and FEM simulation of metal forming processes.

Mahmoud Shariati received his PhD degree in Mechanical Engineering in 1999 from Tarbiat Modares University, Iran and is currently a Professor of Mechanical Engineering at Ferdowsi University of Mashhad, Iran. To date, he has published more than 124 journal and 64 conference papers. His research interests include fatigue and fracture mechanics, nano-mechanics, stress analysis, and experimental mechanics. 